Zagadnienia Rodzajów Literackich, LX, z. 3

PL ISSN 0084-4446

DOI: $10.26485 / Z R L / 2017 / 60.3 / 11$

Olga LaBendowicz

Uniwersytet Łódzki*

\title{
Participatory Audiovisual Translation in the Age of Immediacy
}

\begin{abstract}
In the age of participatory culture and post-translation, the liberalization of the domain of audiovisual translation (AVT) was only a matter of time. The key four factors which have contributed to this demotic turn include: Linguistic Competence, Availability, Immediacy, and Free-of-Chargeness. Amateur and fan-produced translations increasingly gain in popularity. Meanwhile, the expectations of the industry towards professional translators has become more challenging than ever. The aim of the presented paper is to explore whether these changes call for a more market-driven approach towards AVT in the age of the opening of the industry for other agents.
\end{abstract}


* Zakład Translatoryki Instytutu Anglistyki Wydziału Filologicznego Uniwersytet Łódzki

ul. Pomorska 171/173, 91-404 Łódź

adres do korespondencji: ul. Źródłowa 41/1, 91-735 Łódź

e-mail: olgalabendowicz@wp.pl 
In 2004 Jorge Díaz Cintas already remarked that, "In numerical terms, the translation carried out in the audiovisual realm is the most important translational activity of our time". Since then, Translation Studies (in general) and AVT (in particular) have undergone a number of changes as far as their key objectives are concerned - the Cultural Turn, which began in 1990s, seems to have paved a way for yet another approach: the Demotic Turn and "the shift towards participatory audiovisual translation" (Luis Pérez-González 2014). These two interrelated phenomena have shed new light on AVT.

In today's digitalized and fast-paced world, audiences' expectations and criticism appear to have taken over the reins. AVT as such has been radically democratized due to the omnipresence of free online tools and immediacy of the Internet. The question remains: what do these entail and what will be the consequences thereof? Will the age of posttranslation (in Edwin Gentzler's terms) call for a more market-driven approach to AVT?

\section{The Fours Horsemen of the Apocalypse}

Back in 1998, Riggs referred to English as "lingua global" or "glottoglobal". Due to the clear dominance of English in the media, cinema, and everyday lives, audiences have become increasingly familiar with the language as a result of which their linguistic competence in English has also visibly improved. According to a survey by TNS OBOP (2015) conducted on a group of 1,000 Polish participants aged above 15 years old, over half of Poles (56 percent) knows at least one foreign language. Most frequently it is English 57 percent of respondents declared basic knowledge thereof. However, already twenty-, thirty- and forty-year-olds evaluated their linguistic skills in English as good.

On the other hand, according to research by Nielsen (2016), although the importance of traditional television has not diminished, more and more people resort to watching audiovisual materials online - as a result of which, web portals and service providers (such as $\mathrm{VoD}$ in Poland) keep adding new productions for viewing (from very short videos, to feature films). Needless to say, there is also a number of undocumented or simply illegal websites which offer immediate and free access to a wide range of films and TV series in the original version (the likes of "watchseries" or "putlockers"), or with some mode of AVT already embedded onto the image (cda.pl). 
Moreover, as Agnieszka Gromkowska points out, "In cyber-space everything is right now; the 'cult of immediacy' typical for modern culture peaks" (1999: 37). This 'cult of immediacy", referred to by John Tomlinson as "the Culture of Speed", rests on "the redundancy or abolition of the middle term", understood here as the impression that "little separates desire and its satisfaction, that, almost as a constant of modern existence, stuff arrives" (2007: 91). Simply put, we want something and we want it now. Including translated productions.

Therefore, Linguistic Competence (of the source text language), Availability (of online tools for rendering amateur translations), Immediacy (of access to online translations) and Free-of-Chargeness (thereof) all result in a great volume of online translations available at hand, often even prior to the official premiere of a given film or a TV series episode on the Polish market.

Although these phenomena undoubtedly make the lives of audiences easier, they may, however, be perceived by the theoreticians and practitioners as the Four Horsemen of the Apocalypse - representing Death (of professional quality translations), Pestilence (of understanding the technical constraints of a given mode of AVT), War (against the elitist character of translations in general), and which in theory, could also bring Famine (for professionals). Notwithstanding this analogy being possibly viewed as an embellishment, what remains clear is that the translational environment for AVT appears to be changing. But what exactly does this change entail?

\section{The Demotic Turn and Participatory Audiovisual Translation}

When Díaz Cintas was writing about AVT as a key translation type of our age, to support this claim, he emphasized the size of audiences it reaches, a wide range of translated products (various film and television genres) as well as "the immediacy of reception". Yet, as he also pointed out: "A clear paradox exists which emphasises the surprising imbalance between the little research on audiovisual translation and its enormous impact on society".

Nevertheless, the volume of studies devoted to AVT gradually increases. As Yves Gambier noticed, "Although scholars have produced a wealth of material in the last two decades, they have tended to limit themselves to a small range of issues, with a certain degree of prescriptivism" (2014: 56). And that poses the real problem: although

interdisciplinarity increasingly characterizes AVT research today, with methods and concepts borrowed from literary studies, sociology, experimental psychology, film studies, reception studies, history and didactics, the frameworks within which much AVT analysis has been and is being conducted remain mainly linguistics, including pragmatics, discourse analysis and cognitive linguistics, as if the verbal component of AVT were sufficient to describe and understand AVT as a process and a product, with its social and ideological impact. (Gambier 2014: 56)

Which, clearly enough, they are not.

Moreover, as El-dali (2011) observed,

the past fifteen years or so have seen the focus of translation studies shift away from linguistics and increasingly to forms of cultural studies. There has also been a shift towards studies that have incorporated models from functional linguistics and Critical Discourse Analysis, locating the text within its sociocultural context. (El-dali 2011) 
Additionally,

More recently, technological advances, which have transformed the working conditions of professional translators and researchers and have spawned new forms of translation, have also produced new areas of research, some linked to the effects of globalization and some to forms of intersemiotic translation. (El-dali 2011)

All this seems to be the realization of "post-translation studies" — a term used by Edwin Gentzler in his 2017 publication Translation and Rewriting in the Age of Post-Translation Studies. In a foreword to the volume, Susan Bassnett stresses that it signifies a need for connection between Translation Studies (TS) and other academic disciplines thus an interdisciplinary approach. This can be easily extended to AVT — the need for incorporating the achievements of other scholarly disciplines (Cultural Studies, Literary Studies, to name just a few) has accompanied AVT since its emergence.

On the other hand,

The recent vigorous appearance of digital technology and the increase of digital telecommunication in the market and in our lives have forced audiences and market agents to reconsider the role of audiovisual translation modes in terms of audience appeal, choice and commercial success. (Chaume 2016)

And this, precisely, is where the paradox mentioned by Díaz Cintas lies.

As Frederic Chaume (2013) identifies, "changes in cinema, theater, TV and DVD consumption, among others all over the world, show that we are facing a new turn in the field of audiovisual translation: the audience's turn. The media broadcasters' monopoly is now over". This "demotic turn" — a term coined in a 2010 publication by Graeme Turner emphasizes the ever-increasing role of ordinary people in today's media" (Turner 2010: 233). Moreover, in audiovisual translation it was "enabled by the democratization of access to digital technologies and the proliferation of collaborative mediation processes", which is at the same time a clear signal that audiovisual translators face the end of their monopoly (Turner 2010: 233), what points to the opening of AVT for other agents.

Finally,

The shift towards participatory audiovisual translation crucially undermines some long-standing tenets of the discipline, including the generalized perception of translators as politically disengaged mediators without agenda of their own prevalent critiques of subtitling and dubbing as exclusively patron-driven activities. (Pérez-González 2014: 233, original bold)

This phenomenon is closely related to the emergence of participatory culture, which Henry Jenkins et.al. define as "a culture with relatively low barriers to artistic expression and civic engagement, strong support for creating and sharing one's creations, and some type of informal mentorship whereby what is known by the most experienced is passed along to novices" (2009: 3). This liberalization of the rules of how and who renders audiovisual translations is already visible online - the sheer volume of amateur or fan-produced translations is constantly growing. 


\section{Liberalizing Audiovisual Translation}

All this is closely related to the audiences' expectations and preferences. As Chaume observes,

in the field of audiovisual translation, young audiences may prefer to consume fansubs instead of traditional subtitles when watching a foreign video. Or voiced-over realities instead of dubbed ones. Or fadubs instead of dubbed cartoons. (Chaume 2016)

This is not surprising if we bear in mind the Availability, Immediacy and Free-of-Chargeness factors of amateur or fan-produced translations. At the same time, "thanks to technology, Internet communities have appeared with the aim of creating (Italian, Spanish, Finnish, etc.) subtitles for American AV productions in order to allow them to have immediate access to new episodes of popular series or new films" (Gambier 2014: 53). Therefore, "we are witnessing an increase in terms of the available content to which users want instant access - and such content is no longer just the product of the entertainment industry" (Georgakopoulou 2012). As a consequence, "The spread of phenomena such as fansubbing, which has resulted in many subtitle files being available over the internet, and crowdsourcing also have an effect that we cannot ignore" (Georgakopoulou 2012).

On the other hand, as Dominique Pelletier observes, "In our digital era, the process of formatting subtitles central to achieving intersemiotic cohesion requires the mastery of subtitling codes and software, to which access has increased with the popularization of open-source platforms" (2016). Moreover, as she adds,

This democratization of subtitling tools lead to a vast increase of both professional and non-professional subtitling practices, such as fansubbing and the subtitling of social media videos. It also contributed to opening the dialogue regarding the constraints of this type of formatting and the changing guidelines associated with broadcasting standards. (Pelletier 2016)

Furthermore, the preferences towards a mode of watching cinematic productions in the original have also altered. As a result,

Now, rather than committing to a collective, uninterrupted movie experience a theatre, the spectator is often alone, mobile and distracted. This means that the film experience becomes fragmented, and changes not only the way films are understood, but it also the way they are made.

(Fairbanks 2016)

Additionally,

As video on demand market continues to expand, online services like Netflix are producing more and more original films. At the same time, these companies acknowledge that their platforms do not match traditional cinema experiences. (Fairbanks 2016)

This tendency may be easily translated into translated productions with viewers much more likely to watch them at home thus more likely applying amateur or fan-produced translations. 
Alas, the liberalization of AVT has its downsides. Although

translated audiovisual content made available through the various distribution channels that exist today reaches a wider audience than any other type of translation.

$(\ldots)$

The audiovisual industry is (...) experiencing an ever-increasing demand for audiovisual translation services, yet at the same time is forced to contend with the reduction of budgets as well as the contraction of timeframes in which these services need to be provided. (Georgakopoulou 2012)

As a result, translators are faced with great expectations, whereas a gap created by the said high demand is easily filled by amateurs, who are expected usually merely to provide translations quickly and for free. Yves Gambier notices that

While two to four years are needed to produce a film (from scriptwriting and the search for financial support through to release and broadcasting), very often only a few days are given to provide the translation. Thus, it is hardly surprising that most people consider AVT as a "problem", or as a "loss", rather than as a creative solution to the problems of international distribution. (Gambier 2014: 45)

Therefore, although the actual translation has to be rendered at a similar speed as an amateur one, the professionally prepared film or an episode of a TV series with a professional translation appears in Poland on the screens in the translated version relatively late. Meanwhile, amateurs prepare their translations and upload them online. Again, almost immediately (as compared to the professional version) and usually free of charge.

As a consequence, as Chaume points out, "The days of decisions taken by just a few agents, used to dictating what audiences like and dislike, are progressively coming to an end" (2016). Let us, hence, reflect on the ways in which these changes might affect AVT.

\section{Towards More Market-Driven AVT?}

If we consider an audiovisual translation rendered by a professional translator to be a product (which it is), and the viewers who chose a given production with such a translation to be the consumers of this product, then the picture would become slightly altered. While, as pointed out by Costales, "we have to bear in mind that the adaptation of video games is a market driven activity and therefore it does not differ substantially from other sectors like cinema or TV" (2012: 404) — the "Big Three" of AVT in Poland (dubbing, subtitling, and voice over) still seems to hold a slightly different position. However, were we to analyze AVT in terms of marketing, it might offer a broader understanding of how AVT is to proceed — both academically and in practice.

First of all,

To understand consumption and its social and cultural significance, $(\ldots)$ it is necessary to observe what people do with the things they get from the market and to ask what part materiality plays in human interactions and rituals; how consumers appropriate, transform, and domesticate objects and their meanings; and to what extent they integrate contemporary cosmologies. That is, why and for what do people want the things they acquire?. (Rosales and Rodrigues 2011) 
In other words: what are the expectations of AVT audiences, what do viewers need the translations for, and which features thereof they value most? In order to fully understand these aspects, let us first differentiate between a "need" and a "want".

According to Rosales and Rodrigues, "A need is defined as a circumstance in which something is necessary, a thing that is wanted or required" (2011). On the other hand, "Want refers to scarcity, the state of being absent, or a desire for something necessary to life". Moreover, "the distinction between needs and wants based on these parameters promoted the association of needs to human nature or to society and of wants to individual choice" (Rosales and Rodrigues 2011). Thus, as the authors point out,

the first can be subjected to objective authoritative knowledge, whereas the second admit guidance and intervention only from the individual experiencing them. Notions such as "the sovereignty of the consumer" or "the undisputed nature of personal taste" rely on the idea that wants, contrary to needs, do not constitute a matter of rational knowledge and exist beyond collective life and social debate. (Rosales and Rodrigues 2011)

Both, needs and wants, are clearly reflected in the expectations and preferences of AVT audiences.

Furthermore, "The Marketing Concept is preoccupied with the idea of satisfying the needs of the customer by means of the product as a solution to the customer's problem (needs)" (Kotler 2000). Nevertheless, already Societal Marketing Concept holds that "this all must be done in a way that preserves or enhances the consumer's and the society's wellbeing" (Kotler 2000). This approach seems logical should it be applied to AVT — after all, all translations shall be aimed at satisfying the audiences' need to understand a source text in translation, and the want to get a high-quality translation.

Although the former is indisputable, the latter is recently posing some difficulties since to know whether the want has been satisfied, we must first clarify what consumer satisfaction entails. According to Giese and Cote, it can be defined as "A summary affective response of varying intensity", "The exact type of affective response and the level of intensity" of which are "likely to be experienced must be explicitly defined by a researcher depending on the context of interest" (2000: 15). Since "A viewer of a film brings to the film their own experiences and influences and this shapes their response" (Snyder 2011: 192), another phenomenon we shall be aware of is the so-called Horizon of Expectations that audiences are likely to exhibit. According to Zhang, it

refers to the set of expectations against which readers perceive the text. It claims that people within the culture share a common set of understandings about what's possible, probable, impossible, etc. ${ }^{1}$. It is exactly our shared Horizon of Expectations that makes our mutual understanding possible and enables people of various cultures to communicate. (Zhang 2013: 1412)

Although the concept was initially applied to Literary Studies, it can be easily adopted in AVT — and what AV audiences now seem to expect from AVT are Immediacy, Availability, and Free-of-Chargeness, all of which, when combined, may very often result in low-quality translations rendered by amateurs or fansubbers/fandubbers. Fast-food-translations of sorts, we consume in numbers, which do not really offer too much of real nourishment.

1 http://faculty.goucher.edu/eng211/readerresponse_theory.htm. 


\section{"Everyone's an expert, and no one is informed": is the customer always right?}

Although it does not seem feasible that film and TV producers would soon resort to amateur translations instead of professionally rendered ones, let us remember that professional translators face great expectations to produce translations extremely quickly.

Meanwhile, audiences have at their disposal multiple platforms where they can easily voice their opinions about films, which often results in criticizing the translations featured in a respective production. However, these critical remarks very often do not take into account the technical constraints of a given mode of AVT. At the same time, in light of their availability and immediacy, online amateur or fan-produced translations (which usually disregard the technical aspects and/or translation strategies and procedures) gain popularity.

As a result, viewers get accustomed to unprofessional translations and are more likely to compare the professionally rendered translation to amateur ones. This, in turn, is often a consequence of the fact that having a considerable linguistic competence in English, they view word-for-word amateur translations as more directly responding to their "want" (as a tool assisting them in improving their linguistic skills ${ }^{2}$ ). In turn, to quote the title of a 2010 article discussing politics by Dr. Gilbert N. Kahn, "Everyone's an expert, and no one is informed". Which, sadly, can be easily used in the discussion devoted to audiovisual translation.

If we were to adapt the golden rule of marketing stating that "the customer is always right" to AVT, we might end up in a professionally undesirable place, where principles and best practices do not really matter. Once again, if we resort to marketing, we may actually realize that this slogan is utterly wrong.

According to Bubba Page, an entrepreneur and the founder of two startup companies, "the customer is not an expert", thus it is part of the actual expert's role "to explain (...) why what you have to offer is the best deal on the market" (2015). He also quotes Bret Larson, CEO and co-founder of a telemedicine software company, who referred to this rule as "one of the most destructive business models". Therefore, as Page adds, one shall "Be interested in (...) customer's experience, but if only one person is upset, do not assume that you need to bend over backwards to rework the entire experience to address one outlier" (Page 2015). Should this be applied to AVT, we might conclude that professional audiovisual translators may easily continue to operate in a non-modified manner, despite the criticism from viewers. This, however, does not provide too many answers as to how academia and practitioners, as well as AVT as such, shall move forward.

\section{Anticipated Consequences and Further Developments}

In the age when personal opinions are considered of almost the same value as facts, what is and what shall be the position of Translation Studies and, by extension, Audiovisual Translation? Where in this problematic ecosystem of interdependence of respective opinions shall be placed a translation itself and its creator, the translator? If translation is the product, and audience is the consumer, should the product be adjusted to more closely meet the needs and wants of the customer?

2 Subtitlling as a tool for learning foreign language has been discussed eg. by d'Ydevalle (2002), Araujo and Costa (2013), European Commission (2011), Talavan (2006), Loing (2010), among others. 


\section{As Georgakopoulou (2012) points out,}

As an industry which has strong links with and is heavily influenced by changes in technology, it is only natural to turn to language technology experts seeking from them solutions to meet the demand and deliver quality end products. All the above is bound to influence the very process of audiovisual translation. (Georgakopoulou 2012)

In the meantime, "Content providers and broadcasters are trying to reach the widest audience possible, while the rapid growth of internet-based video has made it increasingly common that subtitles accompany streamed and downloaded content" (Georgakopoulou 2012). What we might observe is the increasing liberalization of AVT and a wide acceptance of amateur and fan-produced translations by audiences in the form of participatory audiovisual translation. This, undoubtedly, may be perceived as a shift from elitarism to egalitarism in AVT.

In light of the demotic turn, it would be definitely beneficial were scholars and practitioners to pay more attention to the needs and wants of audiences in order to first, understand them better, and second, to try to integrate some of these into the theoretical and practical approaches. And eventually to find a common ground that would be satisfactory to all parties.

After all, as Jorge Díaz Cintas emphasized,

It is of little benefit to us or our society to shut ourselves away in an ivory tower and draw up theories with no empirical base, to produce a practical work that has no theoretical base, or to teach processes that have nothing to do with the reality of the workplace and have no solid theory behind them. (Díaz Cintas 2004)

Following the scholar's recommendation:

To gain visibility and to assure the social welfare of translation, we need to join forces and avoid the creation of an unnecessary schism between the three dimensions, each as indispensable as the others. (Díaz Cintas 2004)

We shall therefore all keep a close eye on the further developments in the field — focusing not only on the industry, but also (or rather mainly) on the ever-changing trends, which have recently brought about and now perpetuate the participatory audiovisual translation. 


\section{Bibliography}

Chaume Frederic (2015), Audiovisual Translation Trends: Growing Diversity, Trends, and Enhanced Localization, "Media Across Borders: Localising TV, Film and Video Games", eds A.Esser, I.R. Smith, M.Á. Bernal-Merino, Routledge, Londyn-Nowy Jork.

- (2013), TheTurn of Audiovisual Translation, "Translation Spaces" 2, John Benjamins.

Díaz Cintas Jorge (2004), Subtitling: the Long Journey to Academic Acknowledgement, "JoSTrans. The Journal of Specialized Translation”, Issue 01, January, http://www.jostrans.org/issue01/art_diaz_cintas.php [access: 24 February 2017].

El-dali Hosni Mostafa (2011), Towards an Understanding of the Distinctive Nature of Translation Studies, "Journal of King Saud University — Languages and Translation", Volume 23, Issue 1, January, http://www.sciencedirect.com/science/article/pii/S2210831910000056 [access: 24 February 2017].

Fairbanks Joseph (2016), The Lone Spectator Phenomena: Video on Demand Versus Baudry's Apparatus Theory, "Edge", August 24, http://sites.dartmouth.edu/edge/2016/08/24/video-ondemand-versus-baudrys-apparatus-theory-and-the-cinematic-experience-of-online-streaming/ [access: 24 February 2017].

Gambier Y. (2014), The Position of Audiovisual Translation Studies [in:] The Routledge Handbook of Translation Studies, eds C. Millán, F. Bartrina, Routledge, Londyn-Nowy Jork.

Georgakopoulou Panayota (2012), Challenges for the Audiovisual Industry in the Digital Age: the Ever-Changing Needs of Subtitle Production, "JoSTrans. The Journal of Specialized Translation", Issue 17, January, http://www.jostrans.org/issue17/art_georgakopoulou.php [access: 24 February 2017].

Gentzler Edwin (2017), Translation and Rewriting in the Age of Post-Translation Studies, Routledge, Abingdon-New York, https://books.google.pl/books?id=BVtuDQAAQBAJ\&printsec=f rontcover\&hl $=\mathrm{pl} \# \mathrm{v}=$ onepage $\& \mathrm{q} \& \mathrm{f}=$ false [access: 24 February 2017].

Giese Joan L., Cote Joseph A. (2000), Defining Consumer Satisfaction, "Academy of Marketing Science Review", January, http://www.proserv.nu/b/Docs/Defining\%20Customer\%20 Satisfaction.pdf [access: 24 February 2017].

Gromkowska Agnieszka (1999), Tożsamość w cyber-przestrzeni - (re)konstrukcje i (re)prezentacje, http://www.kulturawspolczesna.pl/sites/default/files/artykuly/4._agnieszka_gromkowska_-_tozsamosc_w_cyber-przestrzeni_-_re-konstrukcje.pdf [access: 24 February 2017].

Jenkins Henry, Clinton Katie, Purushotma Ravi, Robison Alice J., Weigel Margaret (2009), Confronting the Challenges of Participatory Culture: Media Education for the 21st Century, MacArthur, https://www.macfound.org/media/article_pdfs/JENKINS_WHITE_PAPER.PDF [access: 24 February 2017].

Kotler Philip (2000), Marketing Management, Upper Saddle River, New Jersey, Prentice Hall, http://www2.nau.edu/ rgm/ha400/class/professional/concept/Article-Mkt-Con.html [access: 24 February 2017].

Media Across Borders. Localizing TV, Film and Video Games (2016), eds A. Esser, M.A. Bernal-Merino, I.R. Smith, https://books.google.pl/books?id=tkR-CwAAQBAJ\&printsec=fron tcover\&hl=pl\# $=$ onepage\&q\&f=false [access: 24 February 2017$]$.

Page Bubba (2016), 3 Reasons Why the Customer Is Always Right... Is Wrong, "Inc.", October 15, http://www.inc.com/bubba-page/3-reasons-why-the-customer-is-always-right-is-wrong. html [access: 24 February 2017]. 
Pallus Patryk (2016), Szykuje sie rewolucja. Dowiemy sie, co ludzie ogladaja w sieci, "Business Insider Polska", http://businessinsider.com.pl/media/nowe-badanie-nielsena-pomiar-telewizji-iinternetu/4rlzzgr [access: 24 February 2017].

Pelletier Dominique (2016), Embedding the Target Text into the Source Text: Subtitling Constraints as Vectors of Translational Creativity, Abstract for I/O [nput/Output] Symposium at the Concordia University, http://iosymposium.tumblr.com/abstracts [access: 24 February 2017].

Pérez-González Luis (2014), Audiovisual Translation: Theories, Methods and Issues, Routledge, https://books.google.pl/books?id=T6FeBAAAQBAJ\&printsec $=$ frontcover\&hl $=\mathrm{pl} \#_{\mathrm{v}}=\mathrm{O}$ nepage\&q\&f=false [access: 24 February 2017].

Riggs Fred W. (1998), Globalization: Key Concepts, http://old.grida.no/geo/GEO/Geo-1-020. htm [access: 24 February 2017].

Rosales Marta, Vilar Rodrigues (2011), Needs and Wants [in:] Encyclopedia of Consumer Culture, SAGE Publications, October 9, http://www.ics.ul.pt/rdonweb-docs/ICS_MRosales_Needs_EDI1.pdf [access: 24 February 2017].

Slater Don (1998), Needs/Wants [in:] Core Sociological Dichotomies, ed. Ch. Jenks, Sage, London.

Snyder Mary H. (2011), Analyzing Literature-to-Film Adaptations: A Novelist's Exploration and Guide, The Continuum International Publishing Group, New York-London, https://books.google.pl $/$ books? $i d=$ nKdIB2Q58r0C\&printsec $=$ frontcover\&hl $=$ pl $\# \mathrm{v}=$ onepage $\& q \& \mathrm{f}=$ false [access: 24 February 2017].

TNS OBOP (2015), Znajomośćjezy/ków obcych, http://www.tnsglobal.pl/wp-content/blogs.dir/9/ files/2015/06/K.041_Znajomosc_jezykow_obcych_O05a-15.pdf [access:24February2017].

Tomlinson John (2007), The Culture of Speed. The Coming of Immediacy, Sage Publications, London-Los Angeles-New Delhi-Singapore, https://books.google.pl/books?id=cZSKBrZ $\mathrm{j} 3 \mathrm{voC} \&$ printsec $=$ frontcover\&hl $=\mathrm{pl} \# \mathrm{v}=$ onepage\&q\&f=false [access: 24 February 2017]. Translating China for Western Readers: Reflective, Critical, and Practical Essays (2014), (eds) M. Dong Gu, R. Schulte, Albany, State University of York, https://books.google.pl/books?id=Id5FB QAAQBAJ\&printsec $=$ frontcover\&hl=pl\# $=$ = onepage\&q\&f=false[access:24February2017].

Turner Graeme (2010), Ordinary People and the Media. The Demotic Turn, Los Angeles-LondonNew Delhi-Singapore-Washington DC, Sage Publishing, https://books.google.pl/book $\mathrm{s} ? \mathrm{id}=\mathrm{sVfAF} 5 \mathrm{FTbMoC} \&$ printsec $=$ frontcover $\& \mathrm{hl}=\mathrm{pl} \# \mathrm{v}=$ onepage\&q\&f$=$ false $[$ access: 24 February 2017].

Zhang Jinfeng (2013), Translator's Horizon of Expectations and the Inevitability of Retranslation of Literary Works, "Theory and Practice in Language Studies", Vol. 3, No. 8, August, http:// www.academypublication.com/issues/past/tpls/vol03/08/16.pdf [access: 24 February 2017]. 